\title{
SOME ASPECTS OF CUMULATIVE RISK
}

\author{
J. KUPPER \\ Zurich, Switzerland \\ INTRODUCTION
}

The classical treatment of stochastic models in non-life insurance is to first derive the well-known Poisson distribution by considering the question of how many claims take place during a definite period $t$. In deriving this distribution the following three assumptions are made:

( I) The population studied is homogeneous.

( II) The occurrence of a claim is a rare event, viz. in an infinitesimal time interval $[t, t+\Delta t]$, the probability of more than one occurrence must be of the order of magnitude $o(\Delta t)$.

(III) The occurrence of any later claim is not influenced by previous ones (no contagion).

In my purely theoretical study [5] ${ }^{1}$ ), the consequences of discarding one or more of the above assumptions were considered. By so generalizing the Poisson distribution, a great many stochastic models can be built, although the results were not always successful. The following study concentrates on some considerations based on assumption (II). The theoretical formulation of the model will be dealt with briefly and the author would first make reference to the instructive article of Thyrion [7] which was unfortunately unknown to him when he was preparing his already mentioned paper. Ammeter [2] and Arfwedson [3] have also considered special cases of this generalization. With the help of the statistics over traffic accidents in the city of Zurich, I hope to throw some more light on the practical aspects of the problem. To the Statistics Office of this city I would express my thanks for kindly placing all documents at my disposal.

\section{THE DISTRIBUTION OF MULTIPLE EVENTS (CUMULATIVE DISTRIBUTION)}

If we accept the three hypotheses mentioned in the introduction,

1) Figures in brackets relate to the list of references at the end of this article, 
the notions of event and claim cannot be distinguished, but the situation changes as soon as (II) is not satisfied. We know from experience that in many branches of insurance the element of multiplicity of the event cannot be simply ignored. It is not necessary to think only of damage from perils such as fire or hail, the problem also arises in life insurance. The question of the total effect on a company of claims arising from a common cause but insured under multiple policies does not appear to have been investigated yet. However, in this study we shall be concerned only with the application to accident insurance, particularly to damage sustained by persons.

An event (i.e. accident), other than one giving rise to purely material damage, will cause injury to, say, $j$ persons $(j=1,2,3, \ldots)$. We denote the conditional probability of occurrence of an accident with multiplicity $j$ by $K_{j}$ and the corresponding "cumulative distribution" by $\left\{K_{j}\right\}$. The latter is therefore defined for $j \geqq \mathrm{I}$, and is, by its nature, discrete. From now on it will be assumed that this distribution is independent of time.

Observed statistics of multiple events often show a markedly skew form with a pronounced maximum for $j=\mathrm{I}$ and a fairly rapid decrease thereafter. A representative example of this is given by van Klinken [4] in respect of traffic accidents in Holland during the year I953 and reproduced in table $I$.

Table I

\begin{tabular}{cc}
\hline $\begin{array}{c}\text { Number of } \\
\text { persons injured }\end{array}$ & $\begin{array}{c}\text { Number of } \\
\text { accidents }\end{array}$ \\
\hline I & I9 3I I \\
2 & I65 \\
3 & I 2 \\
4 & 6 \\
5 & 5 \\
6 & 2 \\
7 & 3 \\
8 & I \\
9 & I \\
Io & I \\
\hline more than Io & 3 \\
\hline Total & I9 5Io \\
Total of injured persons & I9 $84 \mathrm{I}$ \\
\hline
\end{tabular}


$99 \%$ of the accidents are in the class of one injured person, and the conclusion might be drawn that in this case no great significance attaches to the influence of multiplicity. In many examples, however, the disparity will be far less extreme.

The question can properly be asked which theoretical models could be considered for representing a cumulative distribution. Without attempting to give an exhaustive study, we would like to give a selection of important possibilities.

Of the simple one-parametric distributions which could be examined owing to their property of having a monotonously decreasing trend, the following are selected:

\section{(A) Poisson distribution.}

To limit the interval of definition of $\left\{K_{j}\right\}$ to $j \geqq \mathrm{r}$, the Poisson distribution must be modified accordingly. This can be done either through a simple translation

$$
K_{j}=e^{-\lambda} \frac{\lambda^{j-1}}{(j-\mathrm{I}) !}, j=\mathrm{I}, 2, \ldots
$$

or by use of a truncation:

$$
K_{j}=\frac{e^{-\lambda}}{\mathrm{I}-e^{-\lambda}} \frac{\lambda^{j}}{j !}, j=\mathbf{I}, 2, \ldots
$$

(B) Geometric distribution.

$$
K_{j}=\frac{\mathrm{I}}{a}\left(\frac{a}{a+\mathrm{I}}\right)^{j}, j=\mathrm{I}, 2, \ldots
$$

(C) Logarithmic distribution.

$$
K_{j}=\frac{\mathrm{I}}{-\log (\mathrm{I}-p)} \frac{p^{i}}{j}, j=\mathrm{I}, 2, \ldots
$$

(D) Discrete Pareto distribution.

$$
\begin{aligned}
& K_{j}=\frac{\mathrm{I}}{\zeta(\delta)} j^{-\delta}, j=\mathrm{I}, 2, \ldots \\
& \text { where } \zeta(\delta)=\sum_{\nu=1}^{\infty} \frac{\mathrm{I}}{v^{\delta}} \text { is the Riemann Zeta-function. }
\end{aligned}
$$


One parameter functions are however not always adequate for practical requirements as their lack of flexibility prevents adequate representation of observed data. It then becomes necessary to use a two parameter distribution of which the following are considered:

(E) Negative binomial distribution.

$$
\begin{aligned}
& K_{j}=\left(\begin{array}{c}
\alpha+j-2 \\
j-\mathrm{I}
\end{array}\right) p^{\alpha}(\mathrm{I}-p)^{j-1}, j=\mathrm{I}, 2, \ldots \\
& K_{j}=\frac{\mathrm{I}}{\mathrm{I}-p^{\alpha}}\left(\begin{array}{c}
\alpha+j-\mathrm{I} \\
j
\end{array}\right) p^{\alpha}(\mathrm{I}-p)^{j}, j=\mathrm{I}, 2, \ldots
\end{aligned}
$$

analogous to the forms (I) and (2).

If, as shown by table $I$, the single claim frequency is dominant it appears valuable to use a device similar to that applied by Aitchison [I].

We first attach a discrete probability $\theta$ to the point $j=\mathrm{I}$, and for $j \geqq 2$ the distribution is expressed by one of the ordinary, oneparametric distribution laws $\left\{\bar{K}_{j}\right\}$. We then have the form

$$
K_{j}= \begin{cases}\theta & j=\mathrm{I} \\ (\mathrm{I}-\theta) \bar{K}_{j}, & j=2,3, \ldots\end{cases}
$$

For examples we shall use distributions (B) and (C) which are then written as follows:

$$
\bar{K}_{j}=\frac{\mathrm{I}}{a}\left(\frac{a}{a+\mathrm{I}}\right)^{j-1}, j=2,3, \ldots
$$

(in the geometric distribution translation and truncation at the point $j=2$ are identical)

and

$$
\vec{K}_{j}=\frac{\mathrm{I}}{-\log (\mathrm{I}-p)} \frac{p^{j-1}}{j-\mathrm{I}}, j=2,3, \ldots
$$

respectively

$$
\bar{K}_{j}=\frac{\mathrm{I}}{-\log (\mathrm{I}-p)-\bar{p}} \frac{p^{j}}{j}, \quad j=2,3, \ldots
$$

\section{THE DISTRIBUTION OF THE NUMBER OF CLAIMS (CLAIM DISTRIBUTION)}

In the practical section we shall consider the cumulative distribution only, but nevertheless the theoretical aspects of the claim distribution will be briefly discussed. 
The occurrence of the events as well as the number of claims at each event is of stochastic origin and follows, say, the distribution law $\left\{P_{v}(t)\right\}$. The expression $P_{v}(t)$ gives therefore the probability of occurrence of $v$ accidents during the interval $t$, where these quantities are to be dealt with as in $\S I .\left\{K_{j}\right\}$ and $\left\{P_{v}(t)\right\}$ can be combined to give the distribution of all the persons injured. This leads to the claim distribution and its expression is, assuming independence between the corresponding stochastic variables:

$$
W_{j}(t)=\sum_{0 \sim 0}^{1} P_{v}(t) K_{j}^{* v}
$$

where regard must be paid to the fact that the number of persons who sustain injury is at least equal to the number of accidents. $K_{j}^{*}$ means the $v$-fold convolution of the distribution $\left\{K_{j}\right\}$ :

$$
K_{j}^{* v}=\sum_{i=v-1}^{j-1} K^{*(v-1)} K_{j-i}
$$

while $K_{j}^{* v}=0$ as soon as $v>j$, and we also have:

$$
K_{j}^{*_{1}}=K_{j} \text { and } K_{j}^{*_{0}}=\left\{\begin{array}{l}
\mathrm{I} \text { for } j=0 \\
\mathrm{o} \text { for } j \neq 0
\end{array}\right.
$$

There is a simple connection between the generating functions of the three distributions. If they are denoted, in order, by $E_{K}(z)$, $E_{P}(z, t)$ and $E_{W}(z, t)$, where by definition

$$
E_{K}(z)=\sum_{r=}^{\infty} K_{r} z^{r},
$$

it is easy to show that

$$
E_{W}(z, t)=E_{P}\left[E_{K}(z), t\right]
$$

while the corresponding moments are related by the formulas:

$$
\begin{aligned}
& \mu_{W}(t)=\mu_{K} \mu_{P}(t) \\
& \sigma_{W}^{2}(t)=\sigma_{K}^{2} \mu_{P}(t)+\mu_{K}^{2} \sigma_{P}^{2}(t)
\end{aligned}
$$


The classical theory assumes that the events being studied occur according to a Poisson process and therefore that

$$
P_{v}(t)=e^{-\Lambda t} \frac{(\Lambda t)^{v}}{v !}
$$

The claim distribution arising from this assumption is a so-called generalized Poisson distribution and with the help of the examples introduced in $\S \mathrm{I}$ for $K_{j}$, the following representations of the process are derived. It is of advantage on occasion to make use of the generating functions.

(A) The two alternatives for $K_{j}$ give two different sets of probabilities, viz.:

and

$$
W_{j}(t)=e^{-\Lambda t} \frac{\lambda^{j}}{j !} \sum_{0=0}^{1}\left(\begin{array}{l}
j \\
v
\end{array}\right) v^{j-v}\left(\frac{\Lambda t e^{-\lambda}}{\lambda}\right)^{0}
$$

$$
W_{j}(t)=e^{-\Lambda t /\left(1-e^{-\lambda}\right)} \frac{\lambda^{j}}{j !} \sum_{0=0}^{\infty} \frac{v j}{v !}\left(\frac{\Lambda t}{e^{\lambda-1}-1}\right)^{0}
$$

The type of this distribution can be better understood if use is made of the generating function. Thus for the second equation we get with the help of

$$
\begin{gathered}
E_{K}(z)=\frac{e^{\lambda z}-\mathrm{I}}{e^{\lambda}-\mathrm{I}} \\
E_{W}(z, t)=\exp \left\{\frac{\Lambda t}{\mathrm{I}-e^{-\lambda}}\left[e^{-\lambda(1-z)}-\mathrm{I}\right]\right\}
\end{gathered}
$$

which represents a Neyman type A distribution.

(B) Using the geometric distribution we can derive the formula:

$$
W_{j}(t)=e^{-\Lambda t}\left(\frac{a}{a+\mathrm{I}}\right)^{j} \sum_{v=0}^{1}\left(\begin{array}{l}
j-\mathrm{I} \\
v-\mathrm{I}
\end{array}\right) \frac{\mathrm{I}}{v !}\left(\frac{\Lambda t}{a}\right)^{v},
$$

which can be alternatively written as:

$$
\begin{gathered}
W_{0}(t)=e^{-\Lambda t} \\
W_{j}(t)=\Lambda t e^{-\Lambda t} \frac{\mathrm{I}}{a}\left(\frac{a}{a+\mathrm{I}}\right)^{j} F_{1}\left[\mathbf{I}-j ; 2 ;-\frac{\Lambda t}{a}\right], j \geqq \mathbf{I}
\end{gathered}
$$


where ${ }_{1} F_{1}$ is the confluent hypergeometric function of Kummer defined by the series:

$$
{ }_{1} F_{1}(\alpha ; \beta ; x)=\sum_{0=0}^{\infty} \frac{\Gamma(\alpha+v)}{\Gamma(\alpha)} \frac{\Gamma(\beta)}{\Gamma(\beta+v)} \frac{x^{v}}{v !}
$$

This distribution is a so-called Polya/Aeppli distribution.

(C) The generating function

$$
E_{K}(z)=\frac{\log (\mathrm{I}-p z)}{\log (\mathrm{I}-p)}
$$

gives for the claim distribution

$$
E_{W}(z, t)=\left(\frac{\mathrm{I}-p z}{\mathrm{I}-p}\right) \frac{\Lambda t}{\log (\mathbf{1}-p)}
$$

and this, we know, is a negative binomial distribution. With the abbreviation

$\frac{\Lambda}{-\log (I-p)}=\alpha>0$, it takes the form:

$$
W_{j}(t)=e^{-\Lambda t}\left(\begin{array}{c}
j+\alpha t-\mathbf{I} \\
j
\end{array}\right) p^{j}
$$

(D) In the case of the discrete Pareto distribution the representation of the generating function

$$
E_{W}(z, t)=\exp \left[-\Lambda t\left(\mathrm{I}-\frac{\mathrm{I}}{\zeta(\delta)} \sum_{v=1}^{\infty} \frac{z^{v}}{v^{\delta}}\right)\right]
$$

cannot be simplified and the claim distribution is complicated.

(E) This can be looked upon as a generalization of (B). We find:

$W_{j}(t)=e^{-\Lambda t}(\mathrm{I}-p)^{j} \sum_{v=0}^{j}\left(\begin{array}{c}j-v+\alpha v-\mathrm{I} \\ \alpha v-\mathrm{I}\end{array}\right) \frac{\mathrm{I}}{v !}\left(\frac{p^{\alpha}}{\mathrm{I}-p} \Lambda t\right)^{v}$

$W_{j}(t)=e^{-\Lambda t /\left(1-p^{\alpha}\right)}(\mathrm{I}-p)^{j} \sum_{v=0}^{\infty}\left(\begin{array}{c}j+\alpha v-\mathrm{I} \\ j\end{array}\right) \frac{\mathrm{I}}{v !}\left(\frac{p^{\alpha}}{\mathrm{I}-p^{\alpha}} \Lambda t\right)^{v}$

respectively. 
It is perhaps not immediately apparent how we can get (16) from (2I) when $\alpha=\mathrm{I}$.

For $j \geqq \mathbf{I}$, we first deduce:

$$
W_{j}(t)=\Lambda t e^{-\Lambda^{\prime} /(1-p)} p(\mathrm{I}-p)^{j-1}{ }_{1} F_{1}\left(j+\mathrm{I} ; 2 ; \frac{p}{\mathrm{I}-p} \Lambda t\right)
$$

Next making use of the Kummer transformation

$$
{ }_{1} F_{1}(\alpha ; \beta ; x)=e^{x}{ }_{1} F_{1}(\beta-\alpha ; \beta ;-x)
$$

as well as of the parametric substitution $p=\frac{\mathrm{I}}{a+\mathrm{I}},(22)$ is transformed to (I 7$)$.

(F) It will be sufficient to give here the generating function which is in general

$$
E_{W}(z, t)=\exp \left\{-\Lambda t\left[\mathrm{I}-z \theta-(\mathrm{I}-\theta) E_{\bar{K}}(z)\right]\right\}
$$

In the special case (9) this can be written as follows:

$$
E_{W}(z, t)=\exp \left\{-\Lambda t\left[\mathrm{I}-z \theta-\frac{(\mathrm{I}-\theta] z^{2}}{\mathrm{I}+a(\mathrm{I}-z)}\right]\right\}
$$

The probabilities and moments of the distribution can then be derived from these formulas in the usual way.

Whilst the use of the Poisson process to describe the occurrence of damage has been widely studied, many attempts have also been made to generalize the model. These efforts have been concentrated mostly on the negative binomial distribution for the reason that this distribution can readily be adapted to many different assumptions. From (I9) it already follows that if hypothesis (II) of page 85 were to be neglected, a negative binomial distribution could be derived. It is also of interest to note that the same result follows for (I) or for (III), so that it is undoubtedly convenient to substitute the negative binomial for the Poisson law. We can suppose for instance that our population is heterogeneous; it then follows that

$$
P_{v}(t)=\int_{0}^{\infty} e^{-\Lambda t} \frac{(\Lambda t)^{v}}{v !} d S(\Lambda)
$$


where a Gamma distribution

$$
d S(\Lambda)=\frac{\mathrm{I}}{\Gamma(h / d)}\left(\frac{\mathrm{I}}{d}\right)^{h / d} e^{-\Lambda / d} \Lambda^{(h / d)-1} d \Lambda
$$

is to be chosen for the structural function.

The process (I4) is now replaced by

$$
P_{v}(t)=\left(\begin{array}{c}
h \\
\bar{d}+v-\mathrm{I} \\
v
\end{array}\right)\left(\frac{\mathrm{I}}{t d+\mathrm{I}}\right)^{h / d}\left(\frac{t d}{t d+\mathrm{I}}\right)^{v}
$$

Some examples will be given to illustrate this generalization (using the same letters as before):

(A) For the truncated form we have now the generating function

$$
E_{W}(z, t)=\left[\mathrm{I}+t d \frac{\mathrm{I}-e^{\lambda(z-1)}}{\mathrm{I}-e^{-\lambda}}\right]^{-h / d}
$$

and the probabilities

$$
W_{j}(t)=\left(\mathrm{I}+\frac{t d}{\mathrm{I}-e^{-\lambda}}\right)^{-h / d} \lambda^{j} \sum_{j=0}^{\infty}\left(\begin{array}{c}
\frac{h}{d}+v-\mathrm{I} \\
v
\end{array}\right) v^{j}\left(\frac{t d e^{-\lambda}}{\mathrm{I}+t d-e^{-\lambda}}\right)^{v}
$$

(B) The geometric distribution leads to

$$
W_{j}(t)=\left(\frac{\mathrm{I}}{t d+\mathrm{I}}\right)^{h / d}\left(\frac{a}{a+\mathrm{I}}\right)^{j} \sum_{i=0}^{1}\left(\begin{array}{c}
\frac{h}{d}+v-\mathrm{I} \\
v
\end{array}\right)\left(\begin{array}{l}
j-\mathrm{I} \\
v-\mathrm{I}
\end{array}\right)\left(\frac{t d}{t d+\mathrm{I}} \frac{\mathrm{I}}{a}\right)^{v}
$$

which, with the help of the hypergeometric function

$$
F\left(\alpha_{1}, \alpha_{2} ; \beta ; x\right)=\sum_{0=0}^{\infty} \frac{\Gamma\left(\alpha_{1}+v\right)}{\Gamma\left(\alpha_{1}\right)} \frac{\Gamma\left(\alpha_{2}+v\right)}{\Gamma\left(\alpha_{2}\right)} \frac{\Gamma(\beta)}{\Gamma(\beta+v)} \frac{x^{v}}{v !},
$$

can be expressed as

$$
\begin{gathered}
W_{0}(t)=\left(\frac{\mathrm{I}}{t d+\mathrm{I}}\right)^{h / d} \\
W_{j}(t)=\left(\frac{\mathrm{I}}{t \bar{d}+\mathrm{I}}\right)^{\frac{h}{d}+1} \frac{h t}{a}\left(\frac{a}{a+\mathrm{I}}\right)^{j} F\left(\mathrm{I}-j, \frac{h}{d}+\mathrm{I} ; 2 ;-\frac{t d}{t d+\mathrm{I}} \frac{\mathrm{I}}{a}\right), j \geqq \mathbf{I}
\end{gathered}
$$


The distribution takes a somewhat simpler form in the special case $h=d$, i.e. when (24) becomes a geometric distribution with the parameter $t d$.

It is then:

$$
\begin{gathered}
W_{j}(t)=\frac{\mathrm{I}}{t d+\mathrm{I}} \\
W_{j}(t)=\left(\frac{\mathrm{I}}{t d+\mathrm{I}}\right)^{2} \frac{t d}{a}\left(\frac{a}{a+\mathrm{I}}\right)^{j} F\left(\mathrm{I}-j, 2 ; 2 ;-\frac{t d}{t d+\mathrm{I}} \frac{\mathrm{I}}{a}\right), j \geqq \mathrm{I} \quad(28)
\end{gathered}
$$

Now using the formula

$$
F(-n, \alpha ; \alpha ;-x)=(\mathrm{I}+x)^{n}
$$

(28) is changed after some easy calculations into

$$
W_{j}(t)=\frac{t d}{(t d+\mathrm{I})^{2}} \frac{\mathrm{I}}{a+\mathrm{I}}\left[\frac{t d(a+\mathrm{I})+a}{(t d+\mathrm{I})(\mathrm{a}+\mathrm{I})}\right]^{j-1}
$$

If the expression in brackets is called $B(t)$, we get:

$$
W_{j}(t)=\frac{t d}{t d+\mathbf{I}}[\mathbf{I}-B(t)] B^{i-1}(t), j \geqq \mathbf{I}
$$

This distribution is of type (8), but with the discrete probability $\theta$ eliminated at point 0 .

(C) Equation (I8) now becomes:

$$
E_{W}(z, t)=\left[\mathrm{I}-\frac{t d}{\log (\mathrm{I}-p)} \log \left(\frac{\mathrm{I}-p z}{\mathrm{I}-p}\right)\right]^{-h / d}
$$

a distribution which could also be derived from heterogeneity supposition (cf. [5]).

\section{THE CUMUlative DISTRIBUTION IN THE LIGHT OF STATISTICS}

The documents put at our disposal include extracts from reports on every kind of traffic accident which occurred in the city of Zurich. The persons involved in these accidents belonged to all classes of road-users, car-drivers or passengers, motor cyclists or bicycle riders, pedestrians or public transport users. The statistics distinguish three main kinds of accidents: 
(a) Accidents in which persons suffered damage, for the present paper of special interest.

(b) Accidents, in which only material damage occurred.

(c) Petty cases, i.e. accidents where the value of damage is not more than Frs. 200.-

It is perhaps not surprising that in a city district the greatest part of the accidents are of category (b). The two others are roughly of the same order of magnitude. For the past two years, the actual numbers were:

Table 2

\begin{tabular}{r|r|l}
\hline & I96I & I962 \\
\hline a) Damage to persons & 2446 & 2206 \\
b) Damage to objects & 3975 & 4298 \\
c) Petty cases & 2318 & 2 I 80 \\
\hline Total & 8739 & 8684 \\
\hline
\end{tabular}

It is noteworthy to mention that the accidents recorded here are of course only those reported to the police. Having regard to the relatively small numbers conclusions must be drawn with considerable caution and must not be overstressed. The number of accidents causing injury to persons includes also cases where death has occurred to one or more of those involved in the accident. It would be valuable to make a closer study of the cumulative distribution relating to fatal accidents. The numbers are, however, too small ( $1962: 56$ accidents with 57 dead persons), and this kind of accident is therefore not separated from the others. Serious accidents are rather the exception in a town as a result of the generally slow speed of vehicles.

We have assumed on page 86 that the cumulative distribution is independent of time. Is this assumption really sound?

To study this question, we have first analysed all the statistical documents on accidents which occurred during the past few years, from June to September. The results are presented in the table 3: 
Table 3

\begin{tabular}{|c|c|c|c|c|c|c|c|c|}
\hline \multirow{2}{*}{$\begin{array}{l}\text { Number of } \\
\text { persons injured }\end{array}$} & \multicolumn{8}{|c|}{ Number of accidents } \\
\hline & I955 & 1956 & I957 & I958 & I959 & I960 & I96I & 1962 \\
\hline $\begin{array}{r}\text { I } \\
2 \\
3 \\
4 \\
5 \\
6 \\
7 \\
8 \\
9 \\
\text { I0 } \\
\text { I I }\end{array}$ & $\begin{array}{r}889 \\
110 \\
21 \\
6\end{array}$ & $\begin{array}{r}84 \text { I } \\
\text { I I } 2 \\
\text { I } 5 \\
4 \\
4\end{array}$ & $\begin{array}{r}900 \\
99 \\
\mathbf{I} 6 \\
2 \\
\text { I } \\
\text { I } \\
\text { I } \\
\text { I }\end{array}$ & $\begin{array}{r}800 \\
\text { IO4 } \\
\text { I I } \\
4 \\
2\end{array}$ & $\begin{array}{r}78 \mathrm{I} \\
84 \\
8 \\
\mathrm{I} \\
\mathrm{I}\end{array}$ & $\begin{array}{r}842 \\
76 \\
16 \\
4 \\
\mathrm{I}\end{array}$ & $\begin{array}{r}852 \\
96 \\
\text { 10 }\end{array}$ & $\begin{array}{r}734 \\
96 \\
8 \\
4 \\
2 \\
2\end{array}$ \\
\hline $\begin{array}{l}\text { Total number } \\
\text { of accidents }\end{array}$ & 1026 & 976 & 1021 & 922 & 875 & 939 & $95^{8}$ & 846 \\
\hline $\begin{array}{l}\text { Total number of } \\
\text { persons injured }\end{array}$ & I 196 & $\operatorname{II} 4^{6}$ & I I 80 & 1078 & 982 & 1063 & 1074 & 988 \\
\hline emp. means $\bar{x}_{j}$ : & I. 166 & I.I74 & I. I 56 & I. I 69 & I. I 22 & I. 132 & I.I2I & I. 168 \\
\hline emp. variances $s_{f}{ }^{2}$ : & $0.2 \mathrm{I}_{4}$ & 0.249 & 0.276 & $0.3 I_{4}$ & 0.147 & o.I87 & 0.127 & 0.263 \\
\hline
\end{tabular}

At a first glance we may reveal considerable fluctuations in the number of accidents, and there appears to be, rather surprisingly, a downward trend. (In that respect, it must not be overlooked that, during the same period, the number of material damages has markedly increased.) It is of interest to make a comparison with some other figures, although the connection is very loose:

Table 4

\begin{tabular}{|c|c|c|c|c|c|}
\hline & I 955 & I959 & $1962 / \mathrm{I}$ & $\begin{array}{c}\text { Incre- } \\
\text { ment } \\
\text { from } 1955 \\
\text { in }\end{array}$ & $\begin{array}{l}\text { Decre- } \\
\text { ment } \\
\text { to } 1962 / \mathrm{I} \\
\%\end{array}$ \\
\hline $\begin{array}{l}\text { Inhabitants } \\
\text { Motor-cars } \\
\text { Motor-cycles } \\
\text { Bicycles }\end{array}$ & $\begin{array}{r}418588 \\
36951 \\
19767 \\
108847\end{array}$ & $\begin{array}{r}43^{6} 475 \\
5555 \mathrm{I} \\
2 \mathrm{I} \text { IO2 } \\
9453^{\mathrm{I}} \\
* \text { day } \\
\end{array}$ & $\begin{array}{r}4407^{84} \\
6696 I^{*} \\
17027^{*} \\
88937^{*} \\
\text { of compu }\end{array}$ & \begin{tabular}{|l|}
$8 \mathrm{I} .2$ \\
tation: 30.
\end{tabular} & $\begin{array}{r}13.9 \\
18.3 \\
9.1961 \\
\end{array}$ \\
\hline
\end{tabular}


In order to be able to compare the cumulative distributions of the different years, the figures of table 3 have been standardised to a total of 1000 accidents. We then obtain the following picture:

\section{Table 5}

\begin{tabular}{|c|c|c|c|c|c|c|c|c|}
\hline \multirow{2}{*}{$\begin{array}{l}\text { Number of } \\
\text { persons injured }\end{array}$} & \multicolumn{8}{|c|}{ Number of accidents } \\
\hline & I 955 & 1956 & 1957 & 1958 & 1959 & I960 & I96I & I962 \\
\hline I & 867 & 862 & $88 \mathrm{I}$ & 868 & 893 & 897 & 889 & 868 \\
\hline 2 & 107 & I I 5 & 97 & I I 3 & 96 & $8 \mathrm{I}$ & 100 & I I 3 \\
\hline 3 & 20 & I 5 & I6 & 12 & 9 & I7 & I I & 9 \\
\hline 4 & 6 & 4 & 2 & 4 & $\mathbf{I}$ & 4 & - & 5 \\
\hline 5 and more & - & 4 & 4 & 3 & I & I & - & 5 \\
\hline
\end{tabular}

The run of these figures suggests that dependence of time may not simply be rejected, the increase of one-claim accidents during the years I959/6r is a little striking. To make, if possible, a more precise statement, we consider the eight columns as independent random samples out of the same population and examine the significance of the means. To test the hypothesis that the means are random sample values we need the test quantity:

$$
F=\frac{\mathrm{I}}{K-\mathrm{I}} \sum_{j=1}^{K} N_{j}\left(\bar{x}_{j}-\overline{\bar{x}}\right)^{2} / \frac{\mathrm{I}}{N-K} \sum_{j=1}^{K}\left(N_{j}-\mathrm{I}\right) s^{2}{ }_{j}
$$

where $K=$ number of samples $\quad \bar{x}_{j}, s_{j}$ as given in table 3 .

$$
N_{i}=\text { sample sizes }
$$

$$
\overline{\bar{x}}=\frac{\mathrm{I}}{K} \sum_{j=1}^{\mathrm{x}} \bar{x}_{j}, N=\sum_{j=1}^{\mathrm{x}} N_{j}
$$

For large sample sizes this quantity is, independent of the basic distribution, distributed approximately as $F$ with $(K-\mathrm{I}, N-K)$ degrees of freedom (see e.g. [6]). The precision, however, improves with approach to normality and equality of the variances.

Substituting the numerical values in (30), we obtain:

$$
F=2.09
$$


From a table of the $F$-distribution we find as significance levels for $(7, \infty)$ degrees of freedom:

$$
\begin{aligned}
& F_{99 \%}=2.64 \\
& F_{95 \%}=2.0 \mathrm{I}
\end{aligned}
$$

These figures do not allow to conclude that a significant difference exists between the means of the different samples.

The opportunity is here taken to mention two other forms of dependence in connection with the cumulative distribution, although these will not be studied in detail.

It is generally known that the frequency of accidents markedly increases during the summer half year, owing to heavy traffic. The question arises therefore, whether this phenomenon could influence the distribution of multiple accidents in the sense that during the summer months a deplacement occurs towards cumulative cases. Quarterly statistics for I962 are given in table 6:

\begin{tabular}{|c|c|c|c|c|}
\hline \multirow{2}{*}{$\begin{array}{l}\text { Number of } \\
\text { persons injured }\end{array}$} & \multicolumn{4}{|c|}{ Number of accidents } \\
\hline & Ist quarter & 2nd quarter & 3rd quarter & $4^{\text {th }}$ quarter \\
\hline $\begin{array}{c}\text { I } \\
2 \\
3 \\
4 \\
5 \\
6 \\
. \\
. \\
. \\
. \\
\text { II }\end{array}$ & $\begin{array}{r}377 \\
44 \\
5 \\
2 \\
1\end{array}$ & $\begin{array}{r}571 \\
66 \\
8 \\
3 \\
1\end{array}$ & $\begin{array}{r}533 \\
73 \\
7 \\
4 \\
2 \\
2\end{array}$ & $\begin{array}{r}45 \mathrm{I} \\
39 \\
\mathrm{I} 3 \\
3\end{array}$ \\
\hline $\begin{array}{l}\text { Total number } \\
\text { of accidents }\end{array}$ & 429 & 650 & $62 I$ & 506 \\
\hline $\begin{array}{l}\text { Total number of } \\
\text { persons injured } \\
\text { means }\end{array}$ & $\begin{array}{r}493 \\
\text { I.I } 49\end{array}$ & $\begin{array}{r}755 \\
\text { I. } 622\end{array}$ & $\begin{array}{r}73^{8} \\
\text { I. } 188\end{array}$ & $\begin{array}{r}580 \\
\text { I. }{ }_{46}^{6}\end{array}$ \\
\hline
\end{tabular}

Table 6

This result tends to support the supposition but further studies would be necessary to be satisfied of its reality. 
The second remark concerns the place of the accident. It is clear that the conditions prevailing on a highway are different from those in a town where, practically all over, speed limits are prescribed. The cumulative accidents should be much more numerous on a

Table $7 a$

\begin{tabular}{|c|c|c|c|c|}
\hline \multirow{3}{*}{$\begin{array}{l}\text { Number of } \\
\text { persons injured }\end{array}$} & \multicolumn{4}{|c|}{ Number of accidents } \\
\hline & \multicolumn{2}{|c|}{ Outer districts } & \multicolumn{2}{|c|}{ Centre districts } \\
\hline & I96r & I962 & I96r & 1962 \\
\hline $\begin{array}{r}\text { I } \\
2 \\
3 \\
4 \\
5 \\
6 \\
\cdot \\
\cdot \\
\cdot \\
\text { I I }\end{array}$ & $\begin{array}{r}784 \\
91 \\
19 \\
3 \\
2\end{array}$ & $\begin{array}{r}744 \\
86 \\
14 \\
9 \\
3\end{array}$ & $\begin{array}{r}944 \\
73 \\
\text { II } \\
3 \\
\text { I }\end{array}$ & $\begin{array}{r}826 \\
86 \\
12 \\
1 \\
1 \\
2\end{array}$ \\
\hline $\begin{array}{l}\text { Total number } \\
\text { of accidents }\end{array}$ & 899 & 857 & 1032 & 928 \\
\hline $\begin{array}{l}\text { Total number of } \\
\text { persons injured } \\
\text { means }\end{array}$ & $\begin{array}{l}1047 \\
\text { I. } 655\end{array}$ & $\begin{array}{l}1020 \\
\text { I.I90 }\end{array}$ & $\begin{array}{l}\text { I I } 4^{\circ} \\
\text { I.105 }\end{array}$ & $\begin{array}{r}\text { I055 } \\
\text { I.137 }\end{array}$ \\
\hline
\end{tabular}

Table $7 b$

(standardized)

\begin{tabular}{l|r|r|r|r}
\hline \multirow{2}{*}{$\begin{array}{l}\text { Number of } \\
\text { persons injured }\end{array}$} & \multicolumn{4}{|c}{ Number of accidents } \\
\cline { 2 - 5 } & Outer districts & \multicolumn{2}{|c}{ Centre districts } \\
\cline { 2 - 5 } & I96I & I962 & I96I & I962 \\
\hline & 872 & 868 & 9 I5 & 890 \\
2 & IOI & I0O & $7 \mathrm{I}$ & 93 \\
3 & 21 & I6 & IO & I3 \\
4 & 4 & II & 3 & I \\
5 and more & 2 & 5 & 1 & 3 \\
\hline
\end{tabular}


highway than on a town street, but even between districts of the same town, some differences can be noted. The city of Zurich is divided into II districts and the number of accidents is given separately for every district. In the preceding tables $7 \mathrm{a}$ and $7 \mathrm{~b}$ we have grouped together and then compared those four districts which have the most important roads leading out of the town and four others which include, for the most part, the city centre.

It is immediately apparent that multiple accidents occur much more often in the outer districts, an unlikely result from random flunctuations. This will, however, not be closer investigated.

Having now considered more or less closely some of the problems which arise in connection with the cumulative distribution we now approach our main task which is to find a theoretical distribution function which suits our needs. We examine the distributions mentioned in $\S \mathrm{I}$, leaving out, however, the more complicated ones, especially (5) and (7).

To estimate the parameters we make use of the method of moments, which is identical with the principle of maximum likelihood for $(A)-(C)$. We then have:

$\left(A_{1}\right) \quad \hat{\lambda}=\bar{x}-\mathrm{I}$

$\left(A_{2}\right) \quad \hat{\lambda} /\left(\mathrm{I}-e^{-\hat{\lambda}}\right)=\bar{x} \quad$ or $\mathrm{I}-\frac{\hat{\lambda}}{2 !}+\frac{\hat{\lambda}^{2}}{3 !}-\ldots=\frac{\mathrm{I}}{\bar{x}}$

(B) $\hat{a}=\bar{x}-\mathrm{I}$

(C) $\frac{\hat{p}}{(\hat{p}-\mathrm{I}) \log (\mathrm{I}-\hat{p})}=\bar{x}$ or $(\mathrm{I}-\hat{p})\left(\mathrm{I}+\frac{\hat{p}}{2}+\frac{\hat{p}^{2}}{3}+\ldots\right)=\frac{\mathrm{I}}{\bar{x}}$

(E) The moments of the distribution (6) are:

$$
\mu=\alpha \frac{\mathrm{I}-p}{p}+\mathrm{I} \quad \sigma^{2}=\alpha \frac{\mathrm{I}-p}{p^{2}}
$$

Hence it follows

$$
\hat{p}=\frac{\bar{x}-\mathrm{I}}{s^{2}}
$$

$$
\hat{\alpha}=\frac{(\bar{x}-\mathrm{I})^{2}}{s^{2}-(\bar{x}-\mathrm{I})}
$$

(F) In general we get for the moments of (8)

$$
\mu_{(K)}=\theta+(\mathrm{I}-\theta) \mu_{(\bar{K})}, \quad \sigma^{2}(K)=(\mathrm{I}-\theta)\left[\theta(\mu(\bar{K})-\mathrm{I})^{2}+\sigma^{2}(\bar{K})\right]
$$


and as for (9)

$$
\mu_{(\bar{K})}=a+2, \quad \sigma^{2}(\bar{K})=a(a+1),
$$

the estimations of the parameters in (8) and (9) can be expressed by:

$$
\hat{a}=\frac{\mathrm{I}}{2}\left(\frac{s^{2}}{\bar{x}-\mathrm{I}}+\bar{x}\right)-\mathrm{I}, \hat{\theta}=\mathrm{I}-\frac{2(\mathrm{I}-\bar{x})^{2}}{s^{2}+\bar{x}(\bar{x}-\mathrm{I})}
$$

(F') In addition to this last estimate there is a further one which can be directly obtained from the observations at the point $j=\mathrm{I}$. For the three distributions (9), (Io) and (II) we have

$$
\begin{gathered}
\hat{\theta}=\frac{x_{1}}{n}, \quad \hat{a}=\frac{\bar{x}+\hat{\theta}-2}{\mathrm{I}-\hat{\theta}} \\
\hat{\theta}=\frac{x_{1}}{n}, \frac{\hat{p}}{(\hat{p}-\mathrm{I}) \log (\mathrm{I}-\hat{p})}=\frac{\bar{x}-\mathrm{I}}{\mathrm{I}-\hat{\theta}} \text { and } \\
\frac{\hat{p}^{2}}{(\hat{p}-\mathrm{I})[\log (\mathrm{I}-\hat{p})+\hat{p}]}=\frac{\bar{x}-\hat{\theta}}{\mathrm{I}-\hat{\theta}} \text { respectively }
\end{gathered}
$$

To obtain a larger amount of data we have taken the combined statistics of the years 1961 and 1962 . The total number of accidents $2446+2206=4652$ is spread over the different classes according to column $I$ of the following table $8 \mathrm{a}$. The calculation of the observed moments gives:

$$
\bar{x}=\mathrm{I} .1468 \text { and } s^{2}=0.2324
$$

Using these figures we get

$$
\begin{aligned}
& \left(A_{1}\right) \quad \hat{\lambda}=0.1468 \\
& \left(A_{2}\right) \quad \hat{\lambda}=0.2805 \\
& \text { (B) } \hat{a}=0.1468 \\
& \text { (C) } \hat{p}=0.235 \mathrm{I} \\
& \left(E_{1}\right) \quad \hat{p}=0.6317, \quad \hat{\alpha}=0.2518 \\
& \text { (F) } \hat{\theta}=0.8925, \quad \hat{a}=0.3650 \\
& \left(F_{1}^{\prime}\right) \quad \hat{\theta}=0.8859, \quad \hat{a}=0.2866 \\
& \left(F_{2}^{\prime}\right) \quad \hat{\theta}=0.8859, \quad \hat{p}=0.3840 \\
& \left(F_{8}^{\prime}\right) \quad \hat{\theta}=0.8859, \hat{p}=0.3146
\end{aligned}
$$


Table $8 a$

\begin{tabular}{|c|c|c|c|c|c|}
\hline \multirow{2}{*}{$\begin{array}{l}\text { Number of } \\
\text { persons injured }\end{array}$} & \multirow{2}{*}{$\begin{array}{l}\text { Recorded } \\
\text { accidents }\end{array}$} & \multicolumn{4}{|c|}{$\begin{array}{l}\text { Expected theoretical number of } \\
\text { accidents according to }\end{array}$} \\
\hline & & $\left(A_{1}\right)$ & $\left(A_{2}\right)$ & $(B)$ & (C) \\
\hline $\begin{array}{c}\text { I } \\
2 \\
3 \\
4 \\
5 \\
6 \\
. \\
\cdot \\
\\
\text { I I }\end{array}$ & $\begin{array}{r}4121 \\
430 \\
71 \\
19 \\
6 \\
4\end{array}$ & $\left.\begin{array}{r}4016.8 \\
589.7 \\
43.3 \\
2.1 \\
\\
\text { O.I }\end{array}\right\}$ & $\begin{array}{r}4030.0 \\
565.2 \\
52.9 \\
3.7 \\
\\
0.2\end{array}$ & $\begin{array}{r}405^{6.5} \\
519.3 \\
66.5 \\
8.5 \\
\\
1.2\end{array}$ & $\begin{array}{r}4080.7 \\
479.7 \\
75.2 \\
13.3\end{array}$ \\
\hline $\begin{array}{l}\text { Total } \\
\quad \chi^{2} \\
\text { degrees of freedom }\end{array}$ & & $\begin{array}{c}415 \cdot 0 \\
2\end{array}$ & $\begin{array}{l}4652 \\
2 \mathrm{I} 5 \cdot 3 \\
2\end{array}$ & $\begin{array}{c}59 \cdot 2 \\
2\end{array}$ & $\begin{array}{c}28.4 \\
3\end{array}$ \\
\hline
\end{tabular}

Table $8 b$

\begin{tabular}{|c|c|c|c|c|c|}
\hline \multirow{2}{*}{$\begin{array}{l}\text { Number of } \\
\text { persons injured }\end{array}$} & \multicolumn{5}{|c|}{$\begin{array}{l}\text { Expected theoretical number of } \\
\text { accidents according to }\end{array}$} \\
\hline & $\left(E_{1}\right)$ & $(F)$ & $\left(F_{1}^{\prime}\right)$ & $\left(F_{a}^{\prime}\right)$ & $\left(F_{s}^{\prime}\right)$ \\
\hline $\begin{array}{l}\text { I } \\
2 \\
3 \\
4 \\
5 \\
6 \text { and more }\end{array}$ & $\begin{array}{r}4 \mathrm{I} 43.9 \\
384 \cdot 3 \\
88.6 \\
24 \cdot 5 \\
7 \cdot 3 \\
3.4\end{array}$ & $\begin{array}{r}415 \mathrm{I} .9 \\
366.4 \\
98.0 \\
26.2 \\
7.0 \\
2.5\end{array}$ & 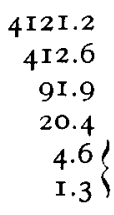 & $\begin{array}{r}4 \mathrm{I} 2 \mathrm{I} .2 \\
420.7 \\
80.8 \\
20.7 \\
5.9 \\
2.7\end{array}$ & $\left.\begin{array}{r}4121.2 \\
415.9 \\
87.2 \\
20.6 \\
5.2 \\
1.9\end{array}\right\}$ \\
\hline $\begin{array}{l}\text { Total } \\
\chi^{2} \\
\text { degrees of freedom }\end{array}$ & $\begin{array}{c}11 \cdot 3 \\
3\end{array}$ & $\begin{array}{c}23 \cdot 3 \\
3\end{array}$ & $\begin{array}{c}4652 \\
10.0 \\
2\end{array}$ & $\begin{array}{l}3 \cdot 5 \\
3\end{array}$ & $\begin{array}{l}5.8 \\
2\end{array}$ \\
\hline
\end{tabular}

What conclusions can be drawn from the above?

Considering the tabulated figures, we can first say that a truncation of $(A)$ gives a better result than a translation. This fact is, however, not general, as a comparison between columns $\left(F_{2}^{\prime}\right)$ and $\left(F_{\mathrm{a}}^{\prime}\right)$ will show. Out of all the one-parametric distributions we have studied, the logarithmic one $(C)$ appears to best represent the data. 
But all these functions have the drawback that the decrease for $j \geqq 4$ is too rapid. The tail can be lifted by the introduction of a second parameter, but the result is not always much better, cf. e.g. example $(F)$.

To provide a statistical test of the various models we have used the $\chi^{2}$-test, grouping those classes with smaller frequency than 2 with the first preceding one. For 2 and 3 degrees of freedom the usual significance limits of the $\chi^{2}$-distribution are:

$$
\begin{array}{lll}
f=2: & \chi^{2}{ }_{95} \%=5.99 & \chi^{2}{ }_{99 \%}=9.2 \mathrm{I} \\
f=3: & \chi^{2}{ }_{95 \%}=7.82 & \chi^{2}{ }_{99} \%=\text { II.34 }
\end{array}
$$

None of the one-parametric distribution functions are satisfactory judged by this test.

Among the two-parameter processes, hypothesis $\left(E_{1}\right)$ turn's out to be only slightly significant. On the other hand, our observations are well represented by $\left(F_{2}^{\prime}\right)$, even better than by $\left(F_{3}^{\prime}\right)$, although there is little to choose between them. A comparison with $\left(F_{1}^{\prime}\right)$ again shows the advantage of using the logarithmic distribution to represent the cumulative risk.

The next step would be to study the effects of the various models on the practical representation of the claim distribution. It is of particular interest to know, when and to what extent the influence of the cumulative distribution may be neglected. However, this must be left for the moment, not without hoping for an investigation of this interesting matter at some future date.

\section{LIST OF REFERENCES}

[I] Aitchison, J.: On the distribution of a positive random variable having a discrete probability mass at the origin. J. Amer. Stat. Assoc. 50 (1955).

[2] Ammeter, H.: Die Ermittlung der Risikogewinne im Versicherungswesen auf risikotheoretischer Grundlage. Mitt. Schweiz. Vers. Math. 57 (1957).

[3] Arfwedson, G.: Research in collective risk theory. Skand. Aktuarietidskrift $3^{8}$ (I955).

[4] Klinken, J. van: Statistical methods to inquire if the risk of accidents has changed. Het Verzekerings-Archief, Actuar. Bijv. XXXIV (1957).

[5] Kupper, J.: Wahrscheinlichkeitstheoretische Modelle in der Schadenversicherung, Teil I: Die Schadenzahl. Blätter der Deutschen Gesellschaft für Versicherungsmathematik 5 (I962).

[6] Pfanzagl, J.: Allgemeine Methodenlehre der Statistik II; Sammlung Göschen, Walter de Gruyter \& Co., Berlin I962.

[7] Thyrion, P.: Note sur les distributions "par grappes". Bull, Ass. Roy. Actuaires Belges 6o (I960). 